\title{
The clinical and social construction of the Paichais of Macau
}

\author{
Chi Chuen Chan ${ }^{1}$ and Keis Ohtsuka ${ }^{2^{*}}$
}

\author{
* Correspondence: \\ Keis.Ohtsuka@vu.edu.au \\ ${ }^{2}$ Victoria University, Melbourne, \\ Australia \\ Full list of author information is \\ available at the end of the article
}

\begin{abstract}
The aim of the present study was to understand the clinical and social construction of pathological gamblers in Macau. In Macau, they are called Paichai (扒仔), which literally means "to grab money from others." This article is a qualitative enquiry into Paichais who gamble in the casinos daily, often for a prolonged period of time. Some Paichais are "resident" gamblers in the casinos who live on the complimentary food and drinks that the casinos provide and sleep on the couches inside the casino premises. To finance their gambling, they hustle and sometimes beg for money. Fifteen participants, ranging in age from 24 to 53 years, were recruited from the casinos in Macau who were repeatedly observed and interviewed. The emphasis of the interviews were to explore the participants' accounts of how their gambling problem had developed and how gambling influenced their lives and their significant others. The Canadian Problem Gambling Index Problem Gambling Severity Index (PGSI) (Ferris \& Wynne, 2001) was used to assess their gambling status. Clinical assessment of the participants was based on the results of clinical interviews, observation notes and the scores on the PGSI. It was found that the majority of the participants could be classified as belonging to the antisocial-impulsive type according to the Blaszczynski and Nower (2002) pathways model of problem and pathological gambling. Paichais can be described as manipulative, cunning, impulsive, reckless and lacking the ability to reflect on their actions. The current study attempts to understand these individuals from the particular social and cultural perspectives of Macau.
\end{abstract}

Keywords: Pathological gambling, Macau, Paichais, Chinese gambling

\section{The clinical and social construction of Paichais of Macau}

The aim of the study was to understand the subjective world and the personality development of Chinese pathological gamblers in Macau. The study recruited active gamblers from the casinos, commonly known as Paichais (扒仔) who form a distinct group of gamblers in the casinos in Macau. Given the recent rapid expansion of the commercial gaming industry in Macau, the stories of the Paichais are important as their stories help us to understand how pathological and problem gambling develop when certain vulnerable personalities interact with gambling opportunities.

Pathological gambling is considered an impulse control disorder according to the Diagnostic and Statistical Manual (4th ed., text rev.) (DSM IV-TR) (American Psychiatric Association, 2000). More specifically, a pathological gambler is an individual who has the urge, whether due to biological heredity and/or behavioural learning, to repeatedly 
gamble despite harmful negative consequences. The gambler and his or her family and community experience the harmful consequences of such behaviour. To diagnose a person as being a pathological gambler, a clinician, usually a psychologist or social worker, needs to ascertain that at least 5 of the following 10 symptoms are present: namely, a preoccupation with gambling, a need to wage or bet a larger amounts of money in order to experience the same level of excitement when gambling, the presence of withdrawal symptoms associated with attempts to stop gambling, gambling to escape from personal problems, chasing after losses, lying to families or co-workers in order to cover up or hide their gambling behaviour, repeated failed attempts to reduce or quit gambling (loss of control), committing illegal acts such as embezzlement and stealing to obtain funds for gambling, and risking significant relationships and needing others to bail out their financial problems (American Psychiatric Association, 2000).

Pathological gambling is a disorder that produced negative consequences not only to gamblers themselves but also to their family with a considerable social cost (Shaffer \& Korn 2002). In Hong Kong, from which many gamblers in Macau originally come from, the most recent prevalence rates in 2011 for possible problem and possible pathological gamblers were 1.9 per cent and 1.4 per cent, respectively (The Hong Kong Polytechnic University 2012). A decreasing trend in the prevalence rates were noted compared to two earlier studies. In 2005, the prevalence rate for probable problem gamblers was found to be $3.1 \%$ and for probable pathological gamblers, 2.2\% (The University of Hong Kong 2005). In 2001, the prevalence rate of probable problem gambling was $4 \%$ and that of problem gambling was $1.8 \%$ (The Hong Kong Polytechnic University 2002).

To date, few studies of gambling have employed a qualitative approach to the personality development of gamblers. The majority of recent studies recruited participants under treatment (e.g., Cheng, 2006; Lam, 2004; Wong et al., 2009). Few studies have included active gamblers in their studies. One exception to this was Chan and his colleagues' ( $\mathrm{Li}$ et al. 2011) investigation of active elderly gamblers in Hong Kong. This study involved twenty participants (12 males and 8 females, $M$ age $=69.3)$. All were interviewed clinically with a semi-structured interview that assessed their development background and gambling history. The Problem Gambling Severity Index (PGSI) (Ferris \& Wynne 2001) was used to assess the nature and extent of their involvement in gambling. The study found that 17 out of 20 participants scored less than two on the PGSI, indicating that the majority of the elderly gamblers in their study were classified as recreational gamblers. Three out of 20 participants could be considered as problem gamblers according to their PGSI scores, which ranged from 8 to 13 . The elderly recreational gamblers in this study did not develop problem gambling despite their life-long involvement in gambling. However, three pathological gamblers, unlike other recreational gamblers in their study, considered gambling a means for attaining personal wealth and seeking excitement. All three had big wins in their adolescence or early adulthood. These findings are consistent with Petry (2002) who found that older pathological gamblers started gambling at an early age and hypothesised that an early big win keeps older gamblers addicted to gambling (Nixon et al., 2005).

Qualitative studies of active pathological gamblers with criminal backgrounds, have been scarce in Hong Kong. Khiatani et al. (2011) conducted a qualitative study on the pathways development of active pathological gamblers with criminal background in Hong Kong. The recruitment of the participants proved to be difficult as they typically 
do not see the need for, and are not amenable to, treatment. Ten participants with criminal backgrounds took part in their study. The Problem Gambling Severity Index of the Canadian Problem Gambling Index (Ferris \& Wynne 2001) and a clinical interview based on the DSM IV-TR (APA, 2000) were administered to obtain a detailed psychological assessment. The results showed that 8 out of 10 participants could be considered as pathological gamblers. These gamblers could be classified as antisocial/ impulsive problem gamblers according to Blaszczynski and Nower's (2002) pathways model of pathological and problem gambling. The characteristics of antisocial gamblers are impulsiveness, lack of moral thinking, and an inability to make rational thinking with regard to gambling. These gamblers did not lead a responsible lifestyle and their motivation to seek treatment was very low or non-existent. One limitation of the investigation was that only Hong Kong participants were included; active casino gamblers in Macau were excluded. Since the increase in the numbers of casinos (34 as at January 2012) has been implicated in the increase in pathological gambling in Macau (Fong \& Ozorio, 2005), the current study of the personality development of casino gamblers in Macau adds to our knowledge of problem gambling in Macau.

The current study is thus intended to fill this gap in knowledge with the aim to understand the subjective world and the personality development of Chinese pathological gamblers in Macau. The study recruited active gamblers from the casinos, commonly known as Paichais (扒仔) who form a distinct group of casino gamblers in Macau. Paichais (扒仔) gamble in the casino every day for prolonged period of time. They can be described as the "resident" gamblers in the casinos as they often live on complimentary food, and nap on the couches in the premises. This study examines the social and clinical construction of Paichais. There were three research aims in the present study: (a) to investigate Paichais' gambling trajectories and social and personality development; (b) to document how Paichais structure their lives around gambling, and (c) to classify Paichais' personality development according to the Blaszczynski and Nower (2002) model of pathological and problem gambling.

\section{Method}

An ethnographic approach (Atkinson \& Hammersley, 1994; Hammersley \& Atkinson, 1995) was employed in the current investigation. The purpose of this ethnographic research was to explore and understand the culture and lifestyle of a specific group through intensive participant observation and detailed interviews. A grounded approach was used for this investigation. Before the commencement of each interview, the researcher did not carry any preconceived perspective on what the data should reveal. Instead, the researcher encouraged participants to tell their stories of gambling in their own voices.

\section{Participants}

The current study recruited only active casino gamblers. Since the target population is highly specific, a purposive sampling was deemed appropriate. However, the elusive nature of Paichais forced the researchers to employ a convenience sampling to investigate Paichais within the casinos that agreed to participate. The aim of the qualitative approach was to understand the themes of gambling in the context of participants' lives 
and experiences (Osborne, 1994). There were 15 participants (9 males and 6 females) with a mean age of 39.6 years ( $S D=9.1$, Age Range, 24 to 53 years). Eleven participants were married and 4 were single. The requirements for inclusion were that they had to be active excessive gamblers within the legal gambling age of 18 or over. This study was also focussed on exploring the personality development of Paichais. In this component of the study, 11 Paichais were recruited. For comparison purposes, the researchers also invited four excessive gamblers, who gamble less intensively than other Paichais, to share their stories. Table 1 shows demographic data of the participants.

The recruitment of the participants, interviews and observations were conducted during the period from July 2009 to March 2010.

\section{Measures}

All participants were interviewed using semi-structured questionnaires that covered their developmental history, gambling habits, career and family development. The interviews were grounded on the DSM-IV-TR diagnosis of pathological gambling (APA, 2000). The interview was conducted in Cantonese, the official language of Hong Kong and Macau. The Problem Gambling Severity Index (PGSI) of the Canadian Problem Gambling Index (CPGI) (Ferris \& Wynne 2001) was administered to all participants. The PGSI is a reliable and well-validated psychological instrument for assessing problem gambling (Jackson et al., 2010; Young \& Stevens, 2008). Scores according to the PGSI are classified into four to indicate the severity of gambling problems: $(0=$ no problems, 1 to $2=$ low risk, 3 to $7=$ moderate risk, and 8 or over $=$ severe problem).

\section{Procedure}

The first author observed gamblers in casinos and vicinity to identify suitable participants and invited them to participate in an interview. In return for their participation,

Table 1 Basic demographics of the participants

\begin{tabular}{lllllllr}
\hline Name & Age & Sex & Marital status & Paichai status & Education & CPGI & Monthly earnings (HKD) \\
\hline Wally & 52 & Male & M & Paichai & Primary & 22 & 15,000 \\
Jenny & 53 & Female & M & Paichai & Primary & 23 & 7,500 \\
Fanny & 48 & Female & M & Paichai & Secondary & 25 & 5,000 \\
Albert & 47 & Male & S & Paichai & Secondary & 25 & 4,500 \\
Heidi & 32 & Female & M & Paichai & Primary & 18 & 4,000 \\
Johnny & 36 & Male & M & Paichai & Secondary & 16 & 5,000 \\
Mark & 40 & Male & M & Paichai & Secondary & 24 & 3,600 \\
Jerry & 52 & Male & M & Paichai & Primary & 19 & 3,500 \\
Mary & 44 & Female & M & Paichai & Secondary & 19 & 7,000 \\
Jennifer & 32 & Female & S & Paichai & Secondary & 20 & 7,000 \\
Tommy & 36 & Male & M & Paichai & Primary & 22 & 6,500 \\
Derrick & 24 & Male & M & Clerk & Post-graduate & 15 & 15,800 \\
Joseph & 28 & Male & S & Apprentice & Secondary & 14 & 6,900 \\
Richard & 32 & Male & S & Salesperson & Secondary & 17 & 8,000 \\
Silvia & 35 & Female & M & Clerk & Secondary & 20 & 20,000 \\
\hline
\end{tabular}

Notes. Marital Status $M=$ Married; $S=$ Single. 
they were offered food coupons as compensation. Ethics approval was obtained from the Human Research Ethics committee of Victoria University, Melbourne, Australia, where the first author completed his PhD (The ethics approval number HRETH 08/92 was granted on the 30th July 2008). All the guidelines of the ethics committee were followed in this study. To ensure the anonymity of the participants, pseudonyms are used in this article where participant interviews are discussed.

Thematic analysis was performed on the collected data. This methodology enabled the researchers to appreciate and understand the subjective experiences and behaviours of the participants. Hycner's explication process (Hycner, 1999) was employed to reveal themes and meanings in the participants' data. In this process, the collected data was grouped together under specific themes, which were further developed into concepts and theories. This methodology enabled the researchers to appreciate and understand the subjective experiences and behaviours of the participants.

\section{Theoretical basis of this study}

The theoretical basis of the present study is Blaszczynski and Nower's (2002) pathways development model of problem gambling. This pathway model classifies problem gamblers into three types: behaviourally-conditioned gamblers, emotionally vulnerable gamblers and problem gamblers with co-morbid impulse control disorders. These three distinct groups of pathological gamblers differ in their personality characteristics and habits, their career development, their attachment to family and the world, and their developmental history. They might, therefore, be expected to benefit from different intervention techniques. In this model, all pathological gamblers can be classified into three groups namely: behaviourally controlled gamblers, emotionally vulnerable gamblers and antisocial-impulsive gamblers. Wood and Griffiths (2007) reported that the majority of the pathological gamblers in their study were emotionally vulnerable gamblers. UK gamblers mainly gambled to escape from the problems of daily living.

\section{Findings}

The Paichais in this study had a more intensive involvement in gambling than the nonPaichais. While all the participants could be classified as problem gamblers, there was significant difference in the PGSI scores for the two sub-groups: Paichais $(M=21.18$, $n=11)$ and non-Paichais $(M=16.5, n=4)$. Further, clinical interviews showed that Paichais' gambling demonstrated many signs of pathological gambling described in DSM IV-TR.

At this extreme end of gambling, the Paichais' worlds revolve around gambling. A typical Paichai's day is structured around gambling. One of the criteria for problem gambling is whether gambling has caused a significant negative impact on work, schoolwork, or relationships. The Paichais structured their lives on gambling only. They were in the casino every day. Gambling occupied almost all of their leisure hours. Even when they were not gambling they preferred to remain around the baccarat tables, discussing with others the patterns of the outcomes, giving advice, and enjoying each other's company in the casinos. Jennifer (a 32 year old Paichai), for instance, went to the casino every day. She had no day job. Every day after she woke up in the morning, she would rush to the casino, enjoying the free complimentary breakfast. Often, she 
would hang around the baccarat tables, busily discussing with others the emerging patterns of the Baccarat hands. Jennifer and other Paichais believe that the indicator display of Baccarat outcomes form symmetric patterns, which recurrently appear. Jerry (a 52 year old male Paichai, originally from Hong Kong) even slept in the casinos as he had lost all his money. At the time of the interviews, he was penniless and had to live on the complementary food provided by the casinos.

Even though the Paichais might come from diverse backgrounds, they shared similar pathway and trajectories in their gambling development. They could best fit into the antisocial-impulsive type of the Blaszczynski and Nower (2002) pathways model of problem and pathological gambling. These gamblers could be described as cunning, manipulative, and lacking empathy. They are egocentric, impulsive, and reckless risk takers who have difficulties in following social norms and rules and in abiding by law and order. They are not motivated for any psychological treatment.

\section{The social and clinical construction of Paichais}

The majority of Paichais reported behavioural problems starting at childhood. Tommy (a 36 year old, male), for instance, had a history of conduct disorders since childhood. Six of the Paichais in the study had criminal records. Very often, their developmental histories were marked with frequent conflicts in families and school. Tommy reported having school problems early in his teens. He told the researcher he had a constant craving for stimulation; he enjoyed physical fights with fellow students and he started to gamble at 10. In fact, the majority of Paichais had disciplinary problems at school. Instances of conduct disorder included truancy, stealing, and promiscuous sexual relationships. They were academic underachievers as only a few had completed high school education.

\section{Always in the action}

Paichais' subjective worlds focused around casino gambling. Not only were they in the casino every day but gambling also occupied almost all of their leisure hours. Even when they were not gambling, they enjoyed remaining around the Baccarat tables, discussing with others the patterns of the outcomes, and giving advice to other gamblers. Johnny (a 52 year old male Paichai) told the researcher that he regarded casinos as his second home as he would go there every day. The Pachais had no stable jobs and they survived on the complimentary food and drinks provided by the casinos. Odd tips they received for offering unsolicited gambling advice, were reinvested straight back on the gambling table. For Paichais, the casinos were their homes. They spent more time in the casinos than anywhere else. This replacement of the home with the casino was especially true for the three Paichais originally from Hong Kong. They had left their homes in Hong Kong, lost everything in gambling, and made the casinos in Macau their home.

\section{Paichais' daily "work"}

The Paichais never considered themselves to be regular patrons in the casinos. They perceived themselves as gambling teachers or gambling masters. Despite a lofty selfaggrandising view as a gambling "shifu" (master), their actual existence is less than grandiose. The Paichais earned meagre and occasional rewards by pestering other gamblers as tip hustlers for small changes or tips. Some anointed themselves as "cheerleaders" 
for other gamblers in luck and others worked as middlemen for loan sharks. While in the casinos, they spent long hours observing the Baccarat tables. In the process, Paichais tried to work out patterns of the draw card outcomes in an attempt to decode particular patterns of dealt cards during a gambling session. This might be interpreted as gambler's fallacy (Coventry, 2002; Delfabbro, 2004; Keren, 1994), which is reinforced by a cognitive bias towards the use of the representativeness heuristic (Tversky \& Kahneman, 1974) and the law of small numbers (Tversky \& Kahneman, 1971). For example, after a series of wins on Banker in baccarat, the gambler would believe that a bet on Player would have a better chance to win.

Jenny (a 52 year old, female Paichai) spent hours observing the patterns of the dealt cards and offering other gamblers tips on gambling. The tips they received from such advice was one of their major incomes. They believed that the card outcomes of the baccarat games should follow a specified and fixed patterns. And their task was to find out such pattern.

\section{Paichais' betting methods}

Paichais did not bet much; usually they would wager less than two hundred dollars on one game. They often spent a long time observing and pondering the patterns of card outcomes before they bet. Albert (a 47 year old, male Paichai) would stay away from "cold" tables (tables with very few customers) that he believed would bring him bad luck. He often employed the maxi-mini method in his betting. In this method, a gambler bets the least possible amount of money on each game. One special betting method in baccarat gambling employed by Albert involved betting $\$ 100$ on the "banker" and \$110 on the "player" for the same hand of cards. In this, he was actually betting $\$ 10$ on the "player." He believed that this method would prolong his playing time.

\section{Paichai's moral view}

Paichais showed little respect for leading a lawful life. Their sole purpose in life was casino gambling. To this end, they would seek every means to finance their wagering and prolong their stay in the casinos. Legal means used included offering gambling tips to other patrons. Also, they would serve as servants for other gamblers by cheering them on and providing emotional support during their gambling.

In addition to these legal means, Paichais engaged in a number of illegal activities. Some Paichais would lie to cheat others of their money. For example, Jerry (a 52 year old male Paichai) lied to strangers on numerous occasions. One of his typical lies was that he had lost his wallet and was stranded in Macau. Another Paichai Mary (a 44 year old Paichai) often pretended to be a sick and handicapped person and asked other gamblers for money. In addition to lying, some Paichais stole money from other gamblers or served as middlemen for illegal loan sharks. None of the Paichais in the study appeared to display any remorse over their gambling and the pain they had inflicted on others.

\section{Attempts to quit, control gambling or seek treatment}

None of the Paichais in the present study have sought treatment for their problems. Most of them said that they were at their happiest in the casinos even though most had suffered great loss in their years of gambling. Out of 11 Paichais, only one, Albert (a 47 year old male Paichai), had made enquiries about the self-exclusion policy in 
the casinos, but he never sent in the application. His motivation to seek treatment was poor.

\section{Discussion}

The current study finds that Paichais are best classified as antisocial-impulsive gamblers according to the Blaszczynski and Nower (2002) model of problem gambling. The current study validates the pathways model. Based on the collected data, the following is the refined model of the personality and gambling development of Paichais (See Figure 1).

All Paichais began gambling socially at an early age (Stage 1). Usually they came from a family that encouraged gambling. They reported having an early win in their gambling development, and gambling was their favourite pastime or fun activity in teenage years. With increased involvement in gambling, Paichais proceeded to the second stage (Stage 2). In this stage, the gamblers spent more time and money on gambling. Consequently, their interest in and commitment to their families were drastically reduced. Conflicts with significant others were often reported at this stage. Complaints of physical and emotional abuse towards family members were common. As the gamblers' preoccupation with gambling escalated, they started to go to the casinos alone and developed a personalized gambling pattern. Such patterns were filled with irrational beliefs and superstitious behaviour. Most reported periods of binge gambling with significant loss of money and time at work. Repeated chasing of losses induced these gamblers to borrow heavily from friends and relatives. Some resorted to borrowing from high interest loan sharks.

The four non-Paichais in the current study can best be described as being at Stage 2 . Their personality characteristics fit well to the behaviourally conditioned problem gamblers of the Blaszczynski and Nower (2002) model. They were not psychologically

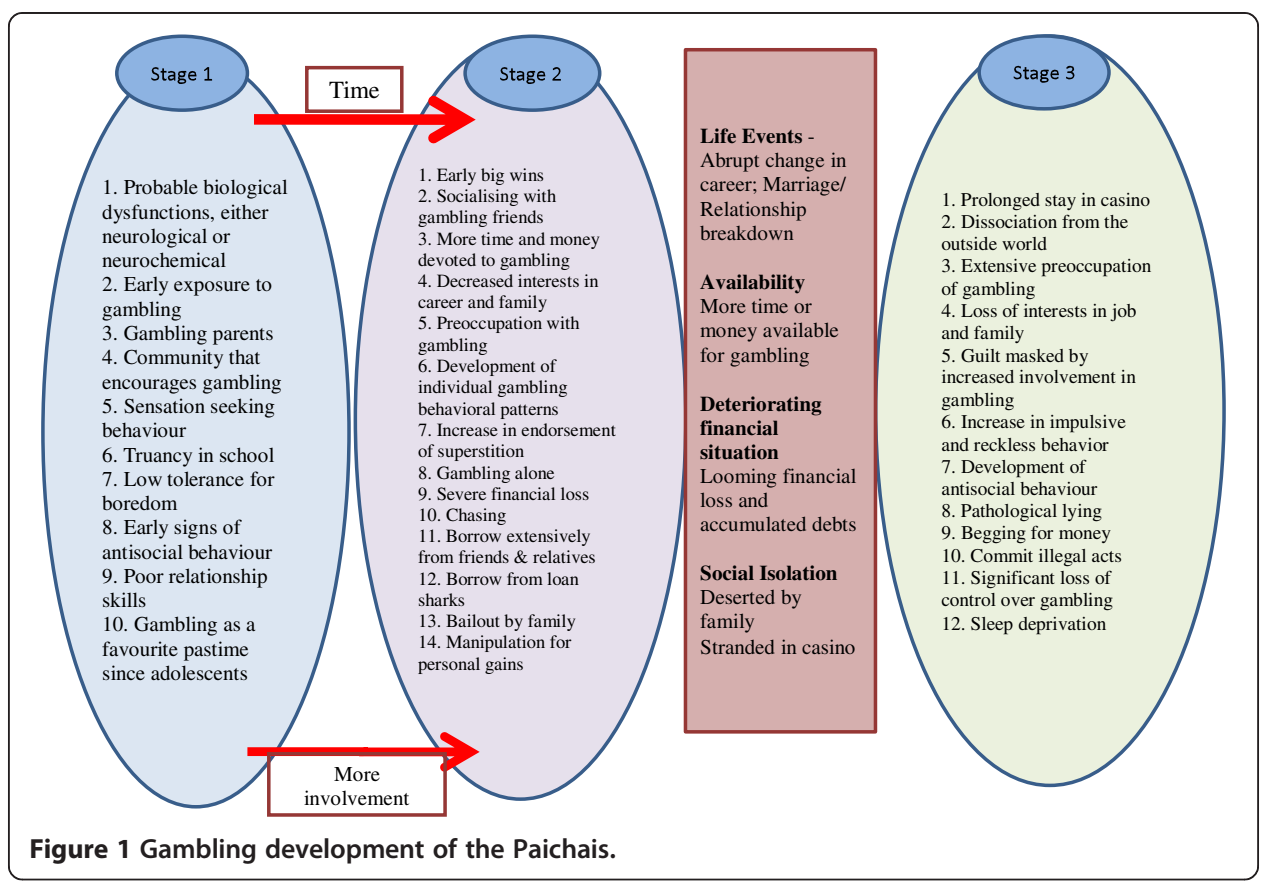


disturbed prior to the development of the gambling behaviour; their emotional problems are the consequences of their gambling. Likewise, Paichais are very different from treatment-seeking gamblers who are mostly behaviourly conditioned gamblers (Chan \& Ohtsuka, 2011). It is interesting to note that all Paichais in the study reported that they had gone through this stage. There are a number of crucial factors that distinguish the gamblers in Stage 2 and the gamblers in Stage 3. These factors are life events such as abrupt changes in the person's career or family, marriage or relationship breakdown, the increase of availability of time and money for gambling, and/or the accumulation of huge gambling debts. All the Paichais in the study are in Stage 3. Other main characteristics that differentiate the Paichais and non-Paichais are the intensity of their preoccupation with gambling and their commitment to maintain a regular job and lifestyle. Paichais are found to be anti-social and impulsive in their gambling. They lack insight into their own problems. These personality characteristics might be the consequences of learning processes and association with other Paichais. Their prolonged stay in the casinos, which dissociate them from the outside world, further contributes for the maintenance of their socially irresponsible behaviour and gambling problems.

The current investigation argues that the pathway development of the antisocial/ impulsive gamblers follows a linear model. All Paichais start as social gamblers. They learned to gamble during childhood or adolescent years. Then as adults, they gambled more intensively, eventually entering Stage 3 of the model. At this stage, their worldview was preoccupied with gambling issues. They were dissociated from their families. They then become "resident gamblers" or Paichais in the casinos. At this stage, they are resistant to professional help. To these Paichais, gambling every day in the casinos provides with them dissociation from their frustrations and failures in life (Brown, 2002; Cavion et al. 2008) and, maybe, also provides a fundamental existential meaning for their lives.

As Langer (1975) demonstrated in her elegant study, illusion of control will increase as the involvement in gambling escalates. As a possible consequence of prolonged hours of gambling in casinos, Paichais reported various cognitive distortions regarding gambling that were entrenched in their views of the world. Gambler's fallacy was frequently reported by Paichais who believed that they would be able to predict dealt cards in baccarat. A resource allocation strategy to increase gambling turnover was used by another Paichai. Paichais in the present study all grew up in a gambling family where gambling had been a norm. Combined with cultural beliefs further reinforce strong cognitive beliefs (see Ohtsuka \& Chan, 2010; Ohtsuka \& Ohtsuka, 2010; Papineau 2005), these cognitive distortions may contribute to the maintenance of gambling behaviour of this unique group of problem gamblers in Macau.

\section{Limitations and implication for future research}

One limitation of the current study stems from the very fact that the study focussed on a very special group of excessive casino gamblers in Macau. By definition, the gambling environment in each jurisdiction is very different. The participants' gambling trajectories and experiences may be solely understood only within the context of Macau casino culture and environment. Nonetheless, this article sheds light on the outcome of the excessive levels of gambling exposure when combined with certain gamblers whose personality type makes them especially vulnerable. 
However, it should also be noted that recruitment of Paichais for this study was very difficult. A combination of convenience and snowball sampling was used. Therefore, our participants were, for better or worse, those people who were willing to tell us their stories. At times, the interviews and observations were carried out in conditions that were less than ideal for the complete and accurate documentation of their actual behaviour and mainly based on their testimonies. The information about the development of gambling is obtained by gamblers' recollection of events in the past. In addition, in order to attain high ecological validity, interviews were conducted in casinos that presented challenges for the researcher. For example, interviews were conducted in the noisy casino environment and notes were then compiled in darkly lit areas. Interviewing recording was not always possible.

Further, some of the participants often refused to talk extensively or their interviews were abruptly cut short while they were gambling. Thus, the entire interviews questions had to be segmented into shorter interviews on multiple occasions. Some Paichais exhibited a limited ability to articulate their views during interviews, perhaps due to their limited education history, and needed to be probed further. The majority of the interview notes were hastily written in the rest rooms in casinos. In collecting the data, the author endeavoured to collect the data by the most reliable means but detailed examinations of their views was difficult.

Future study is recommended to examine the cognitive structure and belief systems of Paichais and how they contribute to sustain their gambling involvement. An investigation of their extensive use of superstitious beliefs in gambling should be another worthwhile investigation.

Competing interest

The authors declare that they have no competing interests.

\section{Authors' contribution}

The article is in part based on CC's PhD research thesis which he completed under KO's supervision. CC drafted this article and $\mathrm{KO}$ contributed through discussion. CC ad $\mathrm{KO}$ revised the manuscript through collaboration. All authors read and approved the final manuscript.

\section{Acknowledgements}

This article is in part based on Chi Chuen Chan's PhD research thesis (Chan, 2011) which was completed under Keis Ohtsuka's supervision.

Author details
${ }^{1}$ University of St. Joseph, Macau, China. ${ }^{2}$ Victoria University, Melbourne, Australia.

Received: 30 January 2013 Accepted: 30 January 2013

Published: 1 March 2013

References

American Psychiatric Association. (2000). Diagnostic and statistical manual of mental disorders (4th ed., text rev.) Washington, DC:. Author.

Atkinson, P, \& Hammersley, M. (1994). Ethnography and participant observation. In NK Denzin \& YS Lincoln (Eds.), Handbook of qualitative research (pp. 248-261). Thousand Oaks, CA: Sage.

Blaszczynski, A, \& Nower, L. (2002). A pathways model of problem and pathological gambling. Addiction, 97, 487-499.

Brown, RIF. (2002). Dissociation phenomena among normal and addicted gamblers. In JJ Marotta, JA Cornelius, \& WR Eadington (Eds.), The downside: Problem and pathological gambling (pp. 201-222). Institute for the Study of Gambling and Commercial Gaming, University of Nevada, Reno.

Cavion, L, Wong, C, \& Zangeneh, M. (2008). Gambling: A sociological perspective. In M Zangeneh, A Blaszczynski, \& NE Turner (Eds.), The pursuit of winning: Problem gambling theory, research and treatment (pp. 95-117). New York: Springer.

Chan, CC. (2011). The clinical and social construction of the Paichais of Macau (Doctoral Thesis, Victoria University, Melbourne, Australia). Retrieved from http://vuir.vu.edu.au/19376

Chan, CC, \& Ohtsuka, K. (2011). Pathways to development of problem gambling among Chinese gamblers in Hong Kong: Validation of the Blaszczynski and Nower (2002) Model. Asian Journal of Gambling Issues and Public Health, 2, 17-28.

Cheng, WK. (2006). From pathological gambling to help seeking: Cases of female pathological gamblers in Hong Kong. (Unpublished Master's thesis) The University of Hong Kong. 
Coventry, KR. (2002). Rationality and decision making: The case of gambling and the development of gambling addiction. In JJ Marotta, JA Cornelius, \& WR Eadington (Eds.), The downside: Problem \& pathological gambling (pp. 43-68). Institute for the Study of Gambling and Commercial Gaming, University of Nevada, Reno.

Delfabbro, P. (2004). The stubborn logic of regular gamblers: obstacles and dilemmas in cognitive gambling research. Journal of Gambling Studies, 20, 1-21.

Ferris, J, \& Wynne, H. (2001). The Canadian Problem Gambling Index: User's manual. Toronto, ON: Canadian Centre on Substance Abuse.

Fong, KC, \& Ozorio, B. (2005). Gambling participation and prevalence estimates of pathological gambling in a far-east gambling city: Macao. UNLV Gambling Research \& Review Journal, 9, 15-27.

Hammersley, M, \& Atkinson, P. (1995). Ethnography: Practices and principles (2nd ed.). New York: Routledge.

Hycner, RH. (1999). Some guidelines for the phenomenological analysis of interview data. In A Bryman \& RG Burgess (Eds.), Qualitative research, (Vol. 3) (pp. 143-264). London: Sage.

Jackson, AC, Wynne, H, Dowling, NA, Tomnay, JE, \& Thomas, SA. (2010). Using the CPGI to determine problem gambling prevalence in Australia: measurement issues. International Journal of Mental Health and Addiction, 8, 570-582. doi:10.1007/ s11469-009-9238-9

Keren, G. (1994). The rationality of gambling: Gamblers' conceptions of probability, chance and luck. In G Wright \& P Ayton (Eds.), Subjective probability (pp. 485-499). Chichester, UK: Wiley.

Khiatani, PV, Yick, KSC, Tse, THM, \& Chan, CC. (2011). Pathways development of Problem Gamblers with criminal background: Validation of Blaszczynski and Nower (2002) model. Paper presented at the 21st National Association for Gambling Studies Annual Conference, Melbourne, Australia.

Lam, KP. (2004). Becoming pathological casino gamblers in Hong Kong: Do big winning experiences matter? Unpublished master's thesis. The University of Hong Kong.

Langer, EJ. (1975). Illusion of control. Journal of Personality and Social Psychology, 32, 311-328.

Li, WL, Lee, LF, Lo, F, Cho, KP, \& Chan, CC. (2011). Recreational gambling among individuals in late adulthood. In Conference Proceedings of the International Conference on Gaming Industry and Public Welfare 2011, Beijing, China (pp. 284-296). ISBN 978-99965-2-036-5.

Nixon, G, Solowoniuk, J, Hagen, B, \& Williams, RJ. (2005). "Double trouble": the lives experience of problem and pathological gambling in later life. Journal of Gambling Issues, 14. doi:10.4309/jgi.2005.14.10

Ohtsuka, K, \& Chan, CC. (2010). Donning red underwear to play mahjong: superstitious beliefs and problem gambling among Chinese mahjong players in Macau. Gambling Research, 22, 18-33.

Ohtsuka, K, \& Ohtsuka, T. (2010). Vietnamese Australian gamblers' views on luck and winning: universal versus culture-specific schemas. Asian Journal of Gambling Issues and Public Health, 1, 34-46.

Osborne, JW. (1994). Some similarities and differences among phenomenological and other methods of psychological qualitative research. Canadian Psychology, 25, 167-189.

Papineau, E. (2005). Pathological gambling in Montreal's Chinese community: an anthropological perspective. Journal of Gambling Studies, 21, 157-178. doi:10.1007/s10899-005-3030-y

Petry, NM. (2002). A comparison of young, middle-aged, and older adult treatment-seeking pathological gamblers. The Gerontologist, 42(1), 92-99.

Shaffer, HJ, \& Korn, DA. (2002). Gambling and related mental disorders: a public health analysis. Annual Reviews Public Health, 23, 171-212. doi:10.1146/annurev.publhealth.23.100901.140532

The Hong Kong Polytechnic University. (2002). A report on a study of Hong Kong people's participation in gambling activities. Author. Retrieved 26 August 2012 from http://www.hab.gov.hk/file_manager/en/documents/whats_new/ gambling/report-eng.pdf

The Hong Kong Polytechnic University. (2012). The study on Hong Kong People's participation in gambling activities. Author. Retrieved 26 August 2012 from http://www.hab.gov.hk/file_manager/en/documents/policy_responsibilities/ others/gambling_report_2011.pdf

The University of Hong Kong. (2005). A study on Hong Kong people's participation in gambling activities. Author. Retrieved 26 August 2012 from http://www.hab.gov.hk/file_manager/en/documents/whats_new/gambling/ KeyStat_200514_e.pdf

Tversky, A, \& Kahneman, D. (1971). Belief in the law of small numbers. Psychological Bulletin, 76(2), 105-110. doi:10.1037/ h0031322

Tversky, A, \& Kahneman, D. (1974). Judgment under uncertainty: heuristics and biases. Science, 185, 1124-1131. doi:10.1126/science.185.4157.1124

Wong, YR, Leung, YKT, \& Lau, CWD. (2009). Behind the allure of gambling: a qualitative exploration of the existential yearnings of Chinese men with problem gambling in Hong Kong. International Gambling Studies, 9, 189-205.

Wood, RTA, \& Griffiths, MD. (2007). A qualitative investigation of problem gambling as an escape-based coping strategy. Psychology and Psychotherapy: Theory, Research and Practice, 80, 107-125.

Young, M, \& Stevens, M. (2008). SOGS and CPGI: parallel comparison on a diverse population. Journal of Gambling Studies, 24, 337-356. doi:10.1007/s10899-007-9087-z

doi:10.1186/2195-3007-3-6

Cite this article as: Chan and Ohtsuka: The clinical and social construction of the Paichais of Macau. Asian Journal of Gambling Issues and Public Health 2013 3:6. 